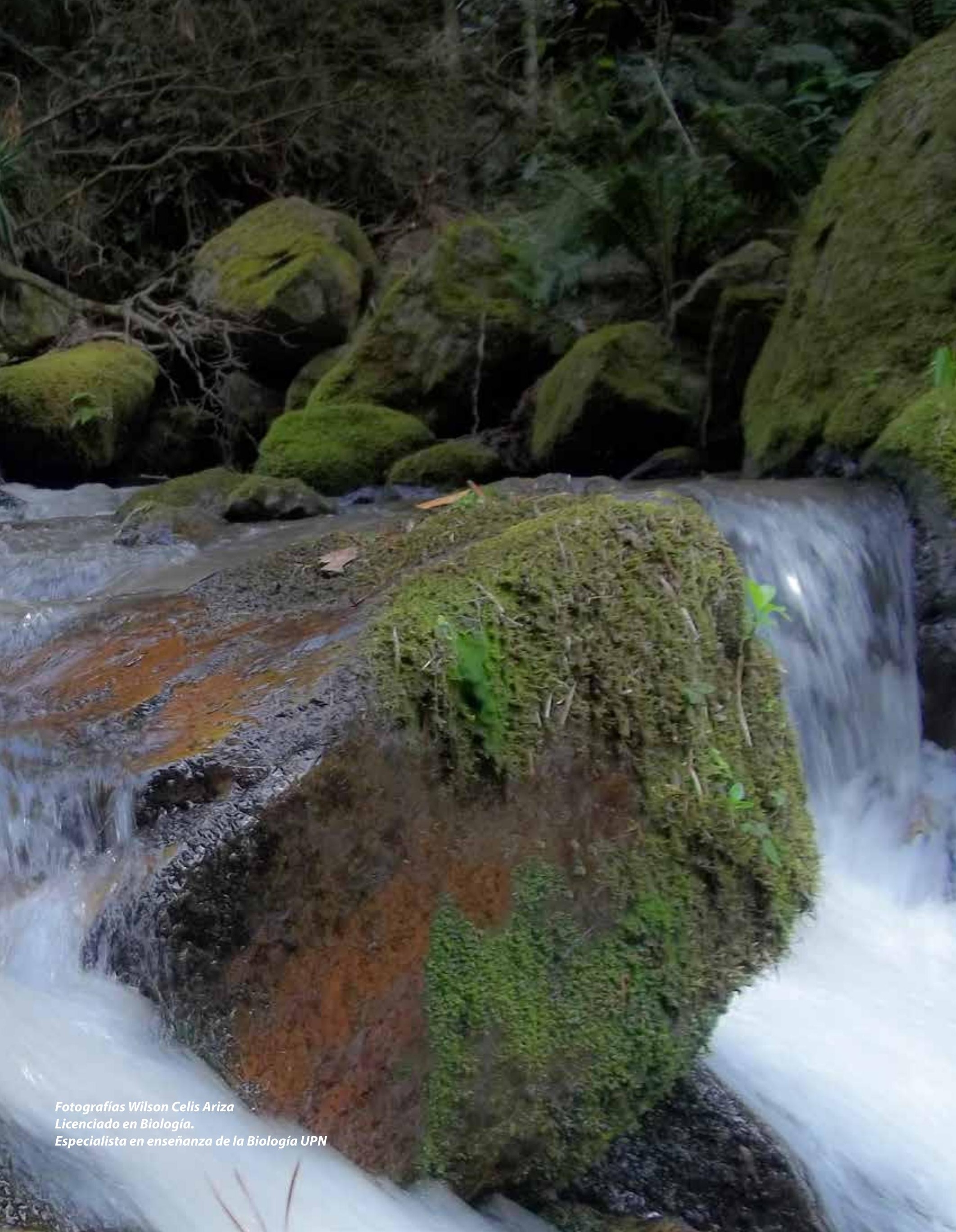




\section{HONGOS APHYLLOPHORALES (BASIDIOMYCOTA) LIGNÍCOLAS DEL BOSQUE ALTO ANDINO"SANTA CLARA". UNA GUÍA ILUSTRADA PARA EL ESTUDIO DE MACROHONGOS}

\section{Aphyllophorales fungi (Basidiomycota) lignicolas of the high Andean forest "Santa Clara". An illustrated guide to the study of Macrofungi}

Fecha de recepción: 15 de agosto de 2014

Fecha de aprobación: 04 de septiembre de 2014

\section{Pinzón-Osorio César Augusto ${ }^{1}$}

\section{DESCRIPCIÓN}

El presente estudio tuvo una duración de dos años y medio y se llevó a cabo en el Bosque Alto Andino Santa Clara (2.585 m.s.n.m.) ubicado en la Vereda Cerca de Piedra, municipio de Chía, como requisito parcial para optar al título de Licenciado en Biología de la Universidad Pedagógica Nacional. La investigación tuvo como objetivo el diseño de una guía ilustrada para la enseñanza de los Macromicetos del orden Aphyllophorales (Basidiomycota), a partir de la descripción taxonómica y respectiva estimación de la composición de estos organismos.

Esta investigación surge de la necesidad de registrar los macrohongos Aphyllophorales de estos ecosistemas, conocidos por estar altamente impactados por la agricultura (Van der Hammen, 2003).

Es fundamental el diseño de un material didáctico que ofrezca un panorama integral sobre la biología de los Aphyllophorales, teniendo en cuenta que las guías de macrohongos para el país, no se orientan directamente a su enseñanza.

\section{Palabras Claves}

Aphyllophorales, Macrohongos, Composición, Guía ilustrada, Enseñanza.

\section{Key Word}

Aphyllophorales, Macrofungi, Composition, Illustrated Guide, Teaching.

1 Licenciado en Biología. Universidad Pedagógica de Colombia. Sede Bogotá. 2014. cesar.fungi20@gmail.com Autor para correspondencia. 


\section{CONTENIDO}

Se muestra la importancia de realizar este tipo de estudios, teniendo en cuenta que la existencia de los bosques y las dinámicas ecológicas dentro de estos, dependen de la presencia de Aphyllophorales como agentes liberadores y recirculantes de nutrientes (Ruiz \& Varela, 2006).

Se ofrecen los referentes conceptuales que sustentaron la investigación con sus respectivos autores. Como resultados, se presenta la composición de Aphyllophorales del Bosque, aportando datos ecológicos, una curva acumulativa que representa el número total de morfoespecies colectadas en cada mes. Además se muestra la relación del número total de colecciones y carpóforos por género de los Aphyllophorales lignícolas colectados. Los hongos se caracterizaron tanto macroscópica como microscópicamente para su identificación con ayuda de claves taxonómicas especializadas.

Por último se expone la Guía llustrada para el estudio de Aphyllophorales y las conclusiones derivadas del trabajo.

\section{FUENTES}

El trabajo cuenta con 108 referentes bibliográficos, de las cuales se destacan:

Alexopoulos, C. \& Mims C. W. (1996). Introducción a la Micología. Ed. Omega, S.A. Barcelona, España. 6-506.

Donk, M. A. (1964). A conspectus of the families of Aphyllophorales. Persoonia 3. 199-224.

Fernández, E. López, A. (2010). Un estudio sobre el uso de álbumes ilustrados en Educación Primaria para la mejora de la competencia intercultural. Una perspectiva europea. Revista de Educación. Consejería de Educación y Cultura de la Región de Murcia. Universidad de Murcia. 358-384.

Franco-Molano A.E. Vasco, A. M. Lopez C, A. \& Boekhout, T. (2005). Macrohongos de la región del medio CaquetáColombia. Guía de Campo. Grupo de taxonomía y ecología de hongos. Universidad de Antioquia. 11-51.

Ruiz, A. \& Varela, A. (2006). Nuevos registros de Aphyllophorales (Basidiomicota) en Bosque Montano Húmedo y de Niebla de Colombia. Caldasia. 28, (2), 259-266.

Van der Hammen, T. (2003). La vegetación Alto-andina de Colombia: Historia, diversidad, ecología y conservación. Memorias. Corporación Autónoma Regional del Quindío. Armenia.

\section{MATERIALES Y MÉTODOS}

El presente estudio es de tipo cualitativo y cuantitativo. El primero enfocándose en el diseño de la Guía Ilustrada, se basó en técnicas, procedimientos y procesos que permiten la construcción de conocimiento complejo desde conceptos no complejos.

El diseño de la Guía se desarrolló en 4 fases. Fase I: Se realizó una revisión bibliográfica que diera cuenta de la necesidad de elaborar la Guía Ilustrada. Fase II: se hizo un inventario de contenidos con descripción de los procedimientos a usar y los conceptos a aplicar. Fase III: se elaboró una conversión del contenido formal a un contenido didáctico. Fase IV: Por último se obtiene la versión definitiva de la Guía en donde la selección y organización de las imágenes siguió lo propuesto por Libedinsky (1995).

El aspecto cuantitativo se basó en la identificación de la composición de Aphyllophorales lignícolas con un diseño de investigación no experimental. El universo de estudio estuvo representado por el Bosque Santa Clara, ubicado en la Vereda Cerca de Piedra. Se presentó un esfuerzo de muestreo de 23 salidas de campo, realizadas desde el año 2011 al 2013. Todas fueron hechas 1 vez por mes y con una duración de 2 horas, recorriendo el sendero con una velocidad aproximada de $3 \mathrm{~km} /$ hora.

Todos los especímenes al momento de la colección fueron fotografiados, especialmente caracteres que pudieran sufrir algún cambio con el tiempo. Se describieron e ilustraron macro y microscópicamente siguiendo lo sugerido por (Franco-Molano et al., 2005). Para el análisis microscopio se utilizó un microscopio digital LCD (TS3).

\section{PRINCIPALES RESULTADOS}

La composición de los Aphyllophorales lignícolas del Bosque Alto Andino estudiado, estuvo representada por 35 morfoespecies, agrupadas en 13 géneros y 7 familias. El mayor número de colecciones fue 46 , pertenecientes al género Corticium.

Se diseñó el texto titulado: Guía Ilustrada para el estudio de Aphyllophorales, que se divide en 5 capítulos que se presenta de manera secuencial y organizada, todas basadas en los parámetros de los contenidos propuestos por Reyes (1989), buscando el interés por parte de los lectores. Los capítulos centrales de la guía ilustrada se dividieron en: generalidades, método de colecta, macroscopía, microscopía y sistematización de datos micológicos de macromicetos. 


\section{CONCLUSIONES}

La familia con mayor tasa de aparición durante el tiempo de muestreo fue Corticiaceae, representada por 2 géneros y 13 morfoespecies, seguida de Polyporaceae, con 5 géneros y 11 morfoespecies.

El género que presentó mayor representatividad en número de carpóforos y de morfospecies fue Corticium seguido por Trametes.

El diseño de la Guía Ilustrada compuesta por fotografías, esquemas, gráficos y dibujos a mano alzada puede explorar de manera didáctica no solo la enseñanza de principios básicos sobre los macrohongos, sino también ofrecer una experiencia directa, facilitando su comprensión y dando elementos teórico-prácticos para que futuros Licenciados en Biología se vinculen al campo micológico.

\section{APORTES EDUCATIVOS DE LA INVESTIGACIÓN}

A partir de la Guía Ilustrada para el estudio de Aphyllophorales, temas muchas veces abstractos en el campo de la micología de macrohongos pueden ser reconocidos de forma vivencial en el momento que el estudiante tiene la oportunidad de conocer, organizar, comparar, determinar y clasificar lo observado, utilizando la información visual y textual. Evitándose así, procesos de memorización de terminología científica y aspectos procedimentales de forma mecánica, arbitraria y textual (Farci, 2007).

Esta Guía Ilustrada es uno de los primeros esfuerzos en el país por construir material didáctico enfocado explícitamente a la enseñanza de los Macrohongos del orden Aphyllophorales. 